\title{
Effect of heating rate on oxidation process of fine-dispersed ZnS:Mn obtained by SHS
}

\author{
Yu.Yu. Bacherikov ${ }^{1 *}$, A.G. Zhuk ${ }^{1}$, O.B. Okhrimenko ${ }^{1}$, D.L. Kardashov ${ }^{2}$, S.V. Kozitskiy ${ }^{2}$, V.V. Kidalov ${ }^{3}$ \\ ${ }^{I}$ V. Lashkaryov Institute of Semiconductor Physics, National Academy of Sciences of Ukraine, \\ 41, prospect Nauky,03028 Kyiv, Ukraine; *e-mail: Yuyu@isp.kiev.ua \\ ${ }^{2}$ Odessa National Maritime Academy \\ 8, Didrikhson str., 65029 Odessa, Ukraine \\ ${ }^{3}$ Berdyansk State Pedagogical University, \\ 4, Shmidta str., 71100 Berdyansk, Ukraine
}

\begin{abstract}
The influence of annealing at $350{ }^{\circ} \mathrm{C}$ in air atmosphere on the luminescent characteristics of powdered $\mathrm{ZnS}$ : $\mathrm{Mn}$ obtained by self-propagating high-temperature synthesis has been studied. It was shown that variation in material heating rate due to changes in the annealing temperature results in different behavior of oxidative processes. It has been ascertained that the slow heating of powdered $\mathrm{ZnS}: \mathrm{Mn}$, compared with the rapid one in the presence of oxygen, promotes active oxidation of $\mathrm{ZnS}$ and formation of Frenkel pairs, increases mileage of defects acting as sensitizers, and their localization near $\mathrm{Mn}^{2+}$. The model which explains the observed changes in the luminescence and PLE spectra has been presented.
\end{abstract}

Keywords: ZnS:Mn, luminescence, oxidation, self-propagating high-temperature synthesis.

Manuscript received 00.00.15; revised version received 00.00.15; accepted for publication 00.00.15; published online 00.00.15.

\section{Introduction}

Phosphors are increasingly used in various semiconductor and display devices. Basic requirements for fluorescent light sources are an effective transformation of the excitation energy to the visible light energy, stable emission in a given spectral range and low power consumption [1]. In this regard, more interests arose to devices based on the phenomenon of electroluminescence (EL) as an alternative to lamps of glowing and gas-discharge [2]. One of the most technologically simple devices based on this phenomenon is an electroluminescent condenser based on powder electrophosphors. One of the advantages of such devices is the possibility to make them flexible, which allows to expand their range of application [3].

To improve the efficiency of phosphor materials, it is necessary to minimize the role of surface states that act as nonradiative recombination channels and have a high impact on the electro-optical characteristics of material. For this purpose, it is responsible to provide the process of encapsulation, i.e. formation of the thin oxide layer on the surface of particles [4]. The standard process for encapsulation of zinc sulfide is provided by formation of a thin $\mathrm{ZnO}$ layer on their surface, which prevents contact of atmosphere with material, thereby enhancing its resistance to degradation. However, during formation of thin oxide layers on the surface of materials such as $\mathrm{A}^{2} \mathrm{~B}^{6}$, it should be taken into account that the fluorescent properties of these materials strongly depends on the concentration of oxygen as an impurity capable to diffuse into the bulk material $[5,6]$.

Therefore, studying the properties of oxygen adsorption and its subsequent behavior, i.e. thin $\mathrm{ZnO}$ layer formation or diffusion into the bulk, which is largely determined by the thermodynamic conditions during its interaction with the surface, is obviously relevant.

The aim of this work is to study by luminescence methods the mechanisms of oxygen behavior in dependence on thermodynamic conditions of interaction with powdered $\mathrm{ZnS}: \mathrm{Mn}$. 


\section{Experimental procedure and results}

Powdered ZnS:Mn was obtained by self-propagating high temperature synthesis (SHS) at temperatures that ensure interaction between zinc and sulfur [7-9]. Doping with the manganese impurity was carried out from $\mathrm{MnCl}$ during synthesis. Ratio of the starting materials was: $\mathrm{Zn}-63 \mathrm{wt} . \%$, $\mathrm{S}-34$ wt. $\%, \mathrm{MnCl}-1$ wt.\%. Heat treatment in air of powdered $\mathrm{ZnS}: \mathrm{Mn}$ was performed in laboratory silica furnace at $350{ }^{\circ} \mathrm{C}$. Temperature conditions of the annealing process were monitored by a thermocouple located in the zone of annealed material. The annealing time was $60 \mathrm{~min}$, the time of reaching $t_{r}$ the temperature of the annealing was 1 and 7 hours. The time of cooling the furnace in all the cases was the same and close to $120 \mathrm{~min}$.

The photoluminescence (PL) and its excitation (PLE) spectra were recorded at room temperature by using SDL-2 monochromator. To excite photoluminescence, radiation of the nitrogen laser LGI-23 $(\lambda=$ $337 \mathrm{~nm}$ ) was used. When registering PLE, excitation of the samples was carried using radiation of a xenon lamp that passed through the monochromator.

The PL spectra of the original and annealed for 7 hours samples, arranged on the basic bands with $\lambda_{\max }=435,456,505,578,600 \mathrm{~nm}$ (curves 2-6). The spectra in Fig. 1 are normalized to the maximum of the band with $\lambda_{\max }=587 \mathrm{~nm}$.

Fig. 1 shows the spectra of PL for the initial and annealed ZnS:Mn samples. As can be seen from the figure, in the PL spectra of powdered ZnS:Mn two bands with $\lambda_{\max }=455,587 \mathrm{~nm}$ dominate. The wide one dominating in the spectrum and possessing $\lambda_{\max } \sim$ $587 \mathrm{~nm}$ is typical for $\mathrm{ZnS}$ doped by Mn. According to [10-12], it consists of several individual bands caused by various localizations of impurity $\mathrm{Mn}$ atoms in the crystal lattice of $\mathrm{ZnS}$. The band with $\lambda_{\max }=600 \mathrm{~nm}$ is associated with $\mathrm{Mn}^{2+}$ ions in octahedral interstices, while the band with $\lambda_{\max }=578 \mathrm{~nm}-$ with $\mathrm{Mn}^{2+}$ ions near dislocations or point defects $[10,11]$ (Fig. 1).

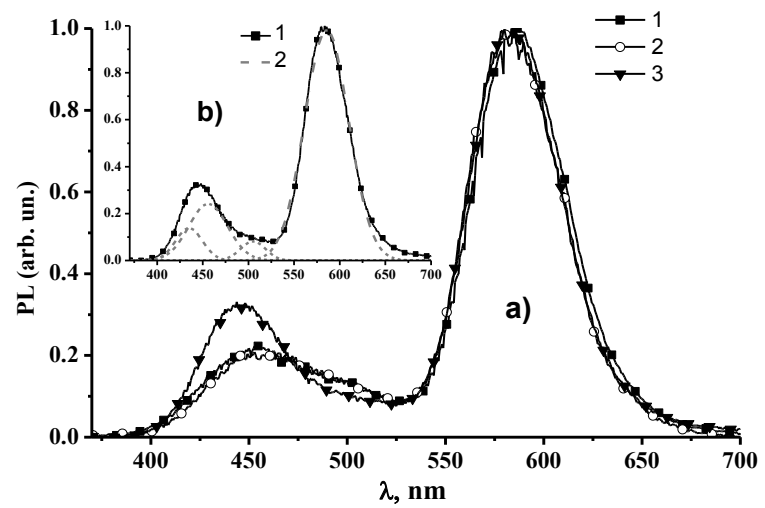

Fig. 1. a) Spectra of PL for initial and annealed $\mathrm{ZnS}: \mathrm{Mn}$ at different speed of a yield of the furnace on annealing temperature, normalized to the maximum of the spectrum. $1-$ initial, 2, 3- $t_{r}$ was 1 and 7 hours, accordingly. b) PL spectrum of annealed $\mathrm{ZnS}: \mathrm{Mn}$ at the heating time 7 hours (1), individual bands composing the spectrum of PL (2).

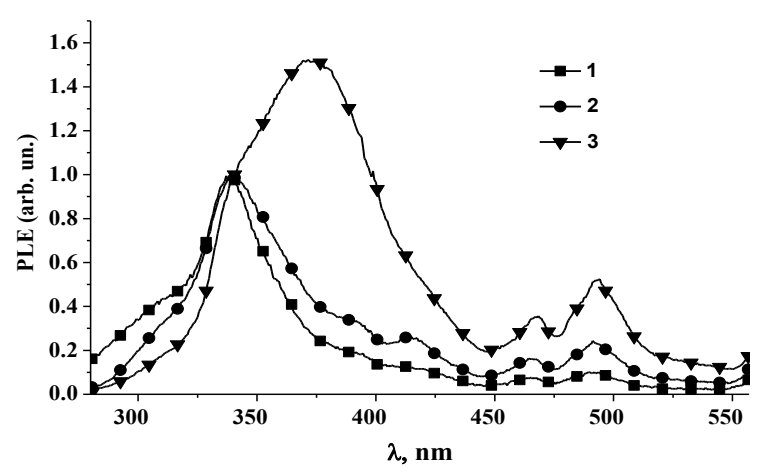

Fig. 2. Spectrum of excitation of luminescence inherent to initial ZnS:Mn (1) and that annealed at different $t_{r}: 1$ hour (2) and 7 hours (3). The spectra are normalized to the maximum of the band-to-band excitation band.

The short-wave band with $\lambda_{\max } \sim 455 \mathrm{~nm}$, which is present in the PL spectrum of $\mathrm{ZnS}: \mathrm{Mn}$, is complex, as it is clearly seen from Figs. 1a and 1b. In this region of PL spectra in $\mathrm{ZnS}$, the following bands are observed: SA band with $\lambda_{\max } \sim 505 \mathrm{~nm}$ is associated with the $\mathrm{V}_{\mathrm{S}}$ [13], $456 \mathrm{~nm}$ band is associated with $\mathrm{V}_{\mathrm{Zn}}-\mathrm{Zn}_{i}$ [14], and the band with $\lambda_{\max } \sim 435 \mathrm{~nm}$, which is due to presence of oxygen in $\mathrm{ZnS}[7,15]$.

Annealing at $T=350{ }^{\circ} \mathrm{C}$ for 1 hour almost didn't led to changes in the spectral characteristics of PL in ZnS:Mn (Fig. 1a). At the same time, at heating the material to an annealing temperature for 7 hours, the intensity of the PL band with $\lambda_{\max }=455 \mathrm{~nm}$ increased to $\sim 1.5$ times as compared to the PL band with $\lambda_{\max }=$ $585 \mathrm{~nm}$, the spectral characteristics of which remain unchanged after annealing. As clearly seen from Fig. 1b, changes in the short-wave region of the PL spectrum of $\mathrm{ZnS}: \mathrm{Mn}$ after heating for 7 hours is due to the increase of the contribution in spectrum of individual bands with $\lambda_{\max } \sim 435$ and $456 \mathrm{~nm}$, which is caused by oxygen impurity and Frenkel pair $\mathrm{V}_{\mathrm{Zn}}-\mathrm{Zn}_{i}[16,17]$, accordingly. Along with it, there is a reduction of the contribution of the band with $\lambda_{\max } \sim 505 \mathrm{~nm}$ due to $\mathrm{V}_{\mathrm{S}}$. The increase in intensity of the PL band with $\lambda_{\max } \sim 435 \mathrm{~nm}$ and decrease in the intensity of the PL band $\lambda_{\max } \sim 505 \mathrm{~nm}$ are probably caused by filling $\mathrm{V}_{\mathrm{S}}$ by oxygen and formation of $\mathrm{O}_{\mathrm{S}}$ centers. Embedding into the $\mathrm{ZnS}$ lattice an atom with the higher electronegativity $(\chi=3.44$ for oxygen [16]), instead of sulfur with the electronegativity $\chi=2.58$ [18], leads to an increase of the electrical moment that is responsible for piezoelectric properties of $\mathrm{ZnS}$. And as it has been shown in the work [19], the presence of the electric moment causes appearance of Frenkel pairs.

PLE spectra of ZnS:Mn, presented in Fig. 2, contain five bands with the maxima located at $\lambda_{\max }=$ 343, 39, 424, 467 and $493 \mathrm{~nm}$. The band at $\lambda_{\max }=$ $340 \mathrm{~nm}$ corresponds to the band of the fundamental excitation for $\mathrm{ZnS}$ [20]. The bands at $\lambda_{\max }=391,424$, 
467 and $493 \mathrm{~nm}$ correspond to those known from the literature $[20,21]$ as elementary manganese bands of PLE. These bands of PLE are caused by transitions from the ground state $\mathrm{Mn}^{2+}{ }^{6} \mathrm{~A}_{1}$ to the excited states ${ }^{4} \mathrm{~T}_{1},{ }^{4} \mathrm{~T}_{2}$, ${ }^{4} \mathrm{E}_{1},{ }^{4} \mathrm{~A}_{1}$ [20]. It is well known [20-22] that the excitation of the $\mathrm{Mn}$ ion is realized with the participation of sensitization centers, whose role in $\mathrm{ZnS}: \mathrm{Mn}$ is performed by closely spaced defects, $\mathrm{Mn}_{\mathrm{Zn}}$, impurities of $\mathrm{Cl}$, O etc.

As seen in Fig. 2, furnace heating for 1 hour leads in essence only to improvement of the efficiency of resonant channels, which involves excitation of $\mathrm{Mn}^{2+}$ luminescence, with respect to the band-to-band channel. At the same time, the heating for 7 hours leads to more significant changes in the PLE spectra. The efficiency of resonant excitation channels of $\mathrm{Mn}^{2+}$ increased even more than when heated for 1 hour, moreover, the growth of the impurity-defect band at $\sim 372 \mathrm{~nm}$ has been so great that it became dominant in the PLE spectra. As was shown by the authors [23], the band in PLE spectra of $\mathrm{ZnS}$ with $\lambda_{\max } \sim 372 \mathrm{~nm}$ is due to the presence of oxygen in the lattice of $\mathrm{ZnS}$, which may indicate active oxygen diffusion into $\mathrm{ZnS}$ under slow heating of material. The increase in intensity of manganese bands in PLE spectra reflects the efficiency of the resonance energy transfer from the sensitizer to the $\mathrm{Mn}$ ion. The change in efficiency of absorption channels of $\mathrm{Mn}^{2+}$ occurs with changes in the symmetry of environment of $\mathrm{Mn}^{2+}$ and sensitization centers as well as their closer mutual localization [24]. In consequence of $\mathrm{ZnS}: \mathrm{Mn}$ heating, there increased is the mobility of $\mathrm{Mn}$ and defects that act as sensitization centers, which ultimately leads to their accumulation in Cottrell atmosphere [25] and closer localization. This, in turn, enhances the effectiveness of resonant excitation channels of $\mathrm{Mn}^{2+}$.

\section{Discussion}

Much more active introduction of oxygen into the lattice of $\mathrm{ZnS}$, when heating during annealing is slow, is supposed to be related with the following events. For adsorption of oxygen on the surface of $\mathrm{ZnS}: \mathrm{Mn}$, it is necessary to overcome an energy barrier $E_{A}$ (see Fig. 3). As temperature increases, the probability to overcome the barrier increases. However, to form association of oxygen with adsorption center it needs some time $(\tau)$. In the ideal case, when there is the coincidence of the energy states of adsorption centers and those of atoms or molecules of oxygen, i.e. the energy of oxygen $E_{\mathrm{O}}$ matches with the barrier height $E_{A}$, the time required for adsorption of oxygen is the lowest one, and $\tau \rightarrow \tau_{0}$. In the case when $E_{\mathrm{O}}<E_{A}$ or $E_{\mathrm{O}}>E_{A}$, oxygen needs the time $\left(\tau_{1}\right)$ to obtain missing energy or to dissipate the excess of energy, then $\tau=\tau_{0}+\tau_{1}$. Thus, if the time of oxygen localization $(t)$ near the adsorption centre is more than $\tau$ $(t \geq \tau)$, then the probability of adsorption is maximal.

When the heating is rapid, the energy of oxygen $\left(E_{\mathrm{O}}\right)$ quickly reaches the value corresponding to that of barrier and quickly begins to significantly exceed it.

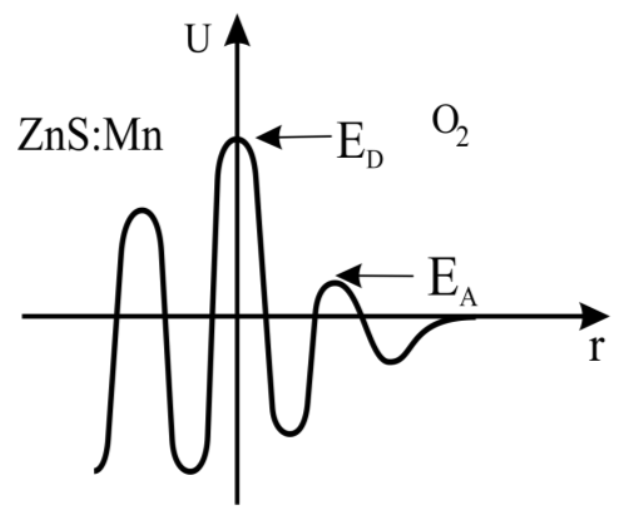

Fig. 3. Potential energy diagram illustrating the required energy of oxygen for participation in the process of its introduction into the lattice of $\mathrm{ZnS}: \mathrm{Mn} . E_{D}$ is the energy when achieving of it diffusion occurs into the bulk.

In this case, i.e. when $E_{\mathrm{O}}>E_{A}$, oxygen has enough energy to overcome the barrier, but the time that oxygen spent at the surface is less than that needed to form stable connection $(t<\tau)$. At the same time, oxygen has enough energy to overcome the barrier in the opposite direction. All this leads to a decrease of the probability of its adsorption and to formation of the thin $\mathrm{ZnO}$ layer or subsequent diffusion of oxygen into the bulk of $\mathrm{ZnS}$. In other words, during rapid heating, even when oxygen has a sufficient energy to physical adsorption, a rapid rise in temperature doesn't accelerate formation of more stable bond and transition in chemically adsorbed state, but converts oxygen to such an energy state, at which the probability of desorption is increased.

In the case of slow heating, when the oxygen reaches the necessary energy to overcome the barrier $\left(E_{\mathrm{O}} \approx E_{A}\right)$, it has enough time to transfer to the physically adsorbed state, and then after getting the extra energy to transfer to the chemically adsorbed state. The further rise in temperature leads to oxygen diffusion into the bulk of material.

\section{Conclusion}

Thus, the processes of oxidation at different heating times proceed differently. These results revealed that the rate of heating of $\mathrm{ZnS}: \mathrm{Mn}$ to the annealing temperature affects on the probability of transition of oxygen from the physically adsorbed to chemically adsorbed state. When heating is more rapid, probability of oxygen desorption from the physically adsorbed state is higher than when the heating is slow.

Furthermore, the slow heating of the material, as compared with the rapid one, in the presence of oxygen promotes active oxidation of $\mathrm{ZnS}$, formation of Frenkel pairs, increase of mileage of defects acting as sensitizers, and their localization near $\mathrm{Mn}^{2+}$, which, in turn, enhances the efficiency of the excitation channels of $\mathrm{Mn}^{2+}$ luminescence. 


\section{References}

1. I.E. Molodetskaia, S.V. Kozitsky, D.D. Polishchuk, Features of structure formation of zinc sulfide produced by self-propagating high-temperature synthesis // Izvestiia AN USSR. Neorganich. materialy, 27, p. 1142-1146 (1991), in Russian.

2. A.N. Georgobiani, Electroluminescence of semiconductors and semiconductor structures // Soros. Education. J., Phys. 6, p. 105-111 (2000).

3. R.G. Valeev, A.N. Bel'tyukov, V.M. Vetoshkin, E.A. Romanov, A.A. Eliseev, Radiation parameters of thin-film electroluminescent emitters based on ZnSe nanocomposite layers // Techn. Phys. 56(6), p. 896-898 (2011).

4. J. Skinner, P.B. Barton, The oxygen for sulfur in wurtzite and sphalerite // Amer. Miner. 45, p. 612 625 (1960).

5. J.M. Poplavko, L.P. Pereverzev, I.P. Raevsky, Physics of Active Dielectrics. Publ. House of the South Federal University, Rostov n/D, 2008.

6. N.J. Sdobniakov, On stability conditions of small particles in the condensed phase // The Bulletin of Tver State University. Phys. Ser. No. 4, p. 158 (2004), in Russian.

7. N.P. Golubeva, M.V. Fok, The oxygen-associated luminescence of "impurity-free" zinc // J. Appl. Spectroscopy, 17, p. 1025-1030 (1972).

8. Y.V. Vorobiev, S. Jiménez-Sandoval, J. GonzálezHernández, S.V. Kozitsky, R.V. Zakharchenko, V.N. Zakharchenko, Electrical and optical properties of semiconducting $\mathrm{ZnS}$ and $\mathrm{ZnMnS}$ ceramics prepared by Self-Propagating High Temperature Synthesis // Superficies y Vacio, 8, p. 37-41 (1999).

9. I.V. Tananaev, V.B. Fedorov, E.G. Kalashnikov, Physics-and-chemistry of energy-saturated media // Uspekhi Khimii, 56, p. 107-120 (1987), in Russian.

10. N.D. Borisenko, M.F. Bulanyi, F.F. Kodzhespirov, B.A. Polezhaev, Properties of emission centers in manganese-doped zinc sulfide // J. Appl. Spectroscopy, 55, p. 911-914 (1991).

11. H.-E. Gummlich, Electro- and photoluminescence properties of $\mathrm{Mn}$ in $\mathrm{ZnS}$ and $\mathrm{ZnCdS} / /$ J. Lumin. 23, p. 73-99 (1981).

12. W. Busse, H. Gumlish, R.O. Tornqvist, V. Tanninen, Angular overlap model for the JahnTeller coupling constants in the orbital triplet states of d5 ions: Case of $\mathrm{Mn}^{2+}$ in $\mathrm{ZnS}$ and $\mathrm{ZnSe} / /$ phys. status solidi (a), 76, p. 553 (1983).

13. T.V. Butkhuzi, A.N. Georgobiani, Ye. Zada-Uly, B.T. El'tazarov, T.G. Khulordava, Luminescence in single-crystal layers of zinc oxide with n- and ptype conductivity // Trudy FIAN, 182, p. 140-187 (1987), in Russian.
14. V.F. Tunitskaya, T.F. Filina, E.I. Panasiuk, Z.P. Ilyukhina, The temperature properties of the individual blue bands of self-activated zinc sulfide and the nature of corresponding radiative centers // J. Appl. Spectroscopy, 14, p. 182-186 (1971).

15. A.N. Georgobiani, M.K. Sheinkman, Physics of $A^{I I} B^{V I}$ Compounds. Nauka, Moscow, 1986 (in Russian).

16. N.K. Morozova, I.A. Karetnikov, V.G. Plotnichenko, E.M. Gavrishchuk, N.V. Yashina and V.B. Ikonnikov, Transformation of luminescence centers in CVD ZnS films subjected to a high hydrostatic pressure // Semiconductors, 38, p. 36-41 (2004).

17. S.V. Bulyarskii and A.S. Basaev, Thermodynamics and kinetics of adsorption of atoms and molecules by carbon nanotubes // J. Experiment. and Theor. Phys. 108, p. 688-698 (2009).

18. CRS Handbook of Chemistry and Physics, in: W.M. Haynes Ph.D. (ed.) Scientist Emeritus National Institute of Standards and Technology, 2007.

19. Yu.Yu. Bacherikov, A.G. Zhuk, S.V. Optasyuk, O.B. Okhrimenko, K.D. Kardashov, S.V. Kozitskiy, The factors influencing luminescent performances $\mathrm{ZnS}: \mathrm{Mn}$, gained by the method a one-phasic synthesis // Semiconductor Physics, Quantum Electronics, Optoelectronics, 15, p. 239247 (2012).

20. M.F. Bulanyi, B.A. Polezhaev, T.A. Prokofiev, I.M. Chernenko, Excitation spectra and structure of luminescence centers of manganese ions in single crystals of zinc sulfide // J. Appl. Spectroscopy, 67 p. 282-286 (2000).

21. T.H. Yeom, Y.H. Lee, T.S. Hahn, Electronparamagnetic-resonance study of the $\mathrm{Mn}^{2+}$ luminescence center in $\mathrm{ZnS}: \mathrm{Mn}$ powder and thin films // J. Appl. Phys. 79(2), p. 1004-1007 (1996).

22. N.K. Morozova, D.A. Mideros, E.M. Gavrishchuk, V.G. Galstyan, Role of background $\mathrm{O}$ and $\mathrm{Cu}$ impurities in the optics of $\mathrm{ZnSe}$ crystals in the context of the model of non-intersecting bands // Semiconductors, 42, p. 131-136 (2008).

23. N.K. Morozova, V.A. Kuznetsov, M.V. Fok, Zinc Sulfide: Preparation and Optical Properties. Nauka, Moscow, 1987 (in Russian).

24. V.F. Agekian, Intracenter transitions of iron-group ions in II-VI semiconductor matrices // Physics of the Solid State, 44, p. 2013-2030 (2002).

25. S.A. Omel'chenko, M.F. Bulanyi, O.V. Khmelenko, Effect of the electric fields of immobile dislocations on photoluminescence and EPR in deformed $\mathrm{ZnS}$ crystals // Physics of the Solid State, 45, p. 1688-1693 (2003). 